\title{
The evolutionary history of body organisation in the lineage towards modern scorpions
}

\author{
Carolin Haug, Philipp Wagner \& Joachim T. Haug
}

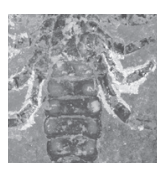

\begin{abstract}
The enormous evolutionary success of euarthropods (insects, crustaceans, myriapods, chelicerates, and their relatives) is generally thought to be coupled to their specific mode of body organisation, also called tagmosis. Their body segments are organised into groups of segments, which share specific functions; these functional units are called tagmata. The patterns of tagmosis differ between the different euarthropod groups, and some of these patterns appear to be constant since the earliest appearance of the group. However, often no strict criteria have been applied which characterise a tagma as such. We provide here a new view on the tagmosis of scorpions and the evolutionary history behind it, by applying criteria already successfully used for elucidating the tagmosis of other euarthropods. Our study shows that the tagmosis changed several times from the ground pattern of Euarthropoda to modern scorpions, the latter ones possessing a tagmosis not present in the earliest scorpions. This difference mainly concerns the region of the sternum, the genital operculum and the pectines. We provide additional data which cast doubt on the presence of pectines in early scorpions. Our argumentation provides an explanation for the evolution of tagmosis in modern scorpions with less conflict than hypotheses proposed earlier. $\bullet$ Key words: tagmosis, tagmatization, feeding apparatus, character polarisation, pectines, book lungs.
\end{abstract}

Haug, C., Wagner, P. \& Haug, J.T. 2019. The evolutionary history of body organisation in the lineage towards modern scorpions. Bulletin of Geosciences 94(4), 389-408 (7 figures). Czech Geological Survey, Prague. ISSN 1214-1119. Manuscript received February 21, 2019; accepted in revised form October 21, 2019; published online December 10, 2019; issued December 31, 2019.

Carolin Haug \& Joachim T. Haug, Department of Biology II, LMU Munich, Biocenter, Großhaderner Str. 2, 82152 Planegg-Martinsried, Germany \& GeoBio-Center of the LMU Munich, Richard-Wagner-Str. 10, 80333 Munich, Germany; carolin.haug@palaeo-evo-devo.info • Philipp Wagner, Department of Biology II, LMU Munich, Biocenter, Großhaderner Str. 2, 82152 Planegg-Martinsried, Germany

No one will argue that among animals, Metazoa, the group Euarthropoda is extremely successful in evolutionary terms. Part of this success has been attributed to one evolutionary "strategy": the stem species of Euarthropoda had a body with numerous segments, each of these segments bearing a pair of appendages, all of these subsimilar (e.g. Maas \& Waloszek 2001; Haug J.T. et al. 2013, fig. 2.3.b, and references therein). Different lineages of Euarthropoda varied this ancestrally uniform body. Several adjacent segments were modified in groups, forming then functional units for specific needs. Such functional units, tagmata, may perform sensory functions, locomotion, feeding, respiration or other tasks.

With this background we should expect that tagmosis, the subdivision of the body into several functional units, evolves within the different lineages of Euarthropoda, leading to very different patterns of body organisation between the different lineages as well as within one lineage (partly this morphological diversity or disparity appears to be a result of developmental plasticity, see e.g. Moczek 2010, Moczek et al. 2011, Minelli 2016 and references therein). Yet, in many lineages the pattern appears to be fixed already quite early within a lineage. For example, Euchelicerata, the group including spiders, scorpions and all their relatives, is generally thought to have a stereotypic tagmosis pattern. The ocular segment and post-ocular segments 1-6 are supposed to form the so-called prosoma; post-ocular segments 7-19 supposedly form the opisthosoma (see Dunlop \& Lamsdell 2017 for a recent discussion). However, when looking closely at many eucheliceratan ingroups this is not quite that obvious or at least not as simple as often stated (see e.g. discussion in Haug C. et al. 2012a).

Here we want to consider the evolution of the tagmosis in modern scorpions. Generally, modern scorpions have been considered to be organised into three tagmata: the prosoma, the mesosoma and the metasoma, the latter two representing subdivisions of the opisthosoma. The prosoma supposedly includes, as mentioned above, the ocular segment and post-ocular segments 1-6. These segments are supposed to dorsally form the prosomal shield. Ventrally, (proximal portions of) appendages of post-ocular segments 1-4 form the feeding apparatus. Appendages of post-ocular segment 1 , the chelicerae, are small pincers that can squash 
and cut prey. Appendages of post-ocular segment 2, the pedipalps, proximally possess endites forming part of the pre-oral chamber. Distally, the pedipalps form large chelae for grabbing prey. Appendages of post-ocular segments 3 and 4 also have proximally endites contributing to the pre-oral chamber. The distal parts of these appendages, as well as those of post-ocular segments 5 and 6 , form the locomotory apparatus.

The mesosoma is supposed to include post-ocular segments 7-14. Post-ocular segment 7 has been considered to be largely reduced (e.g. Dunlop \& Lamsdell 2017, other interpretation further below). All further post-ocular mesosomal segments possess dorsally a separate sclerotisation, a tergite. Post-ocular segment 8 bears the genital opening and operculum covering it, as appendage derivative. Post-ocular segment 9 bears specialised structures for mechano- and chemoreception, the so-called pectines. Post-ocular segments 10-13 have prominent ventral sclerotisations (sternites). Each of these has a pair of openings leading to internalised book lungs. Post-ocular segment 14 also has a tergite and a sternite, but narrows posteriorly and does not bear book lungs.

The metasoma supposedly includes post-ocular segments 15-19. All these do have a tergite and a sternite each, but tergite and sternite are laterally conjoined to form ring segments. Posterior to the last segment, the telson bears the anal opening (the anal opening is often shifted anteriorly into the membrane between last segment and telson) and forms a venom sting.

We aim here at reconstructing the ground pattern states for the tagmosis for all early successive nodes within Euchelicerata until the node of modern scorpions. We will evaluate the functional units at all of these to recognise possible changes in the composition of the tagmata.

\section{Material and Methods}

Data basis. - We try to integrate available information on the body organisation of representatives of Euchelicerata from three different sources: 1) of modern-day adult representatives, 2) of modern-day immature stages, and 3) of fossil representatives.

Data are largely taken from literature. Additional observations on fossil material are provided as well. The directly investigated fossil specimens are from the collections of the Natural History Museum London (NHM) and from the Royal Ontario Museum Toronto (ROM). Interpretations, especially those deviating from original ones, are presented as schematic drawings.

Documentation methods. - Fossil specimens were documented with a Canon Rebel T3i camera, equipped either with an EF-S $18-55 \mathrm{~mm}$ lens or an MP-E $65 \mathrm{~mm}$ macro lens, depending on the size of the structures of interest. For photography under cross-polarised whitelight conditions, a Canon MT 24-EX Macro Twin Flash was used. Polarisation filters were attached to the light sources, and a perpendicularly oriented polarisation filter was place in front of the lens to achieve polarised light. To overcome limitations in depth of field, image stacks were taken with different focal planes. To overcome limitations in field of view, the image stacks were taken of adjacent areas of the specimen with some overlap. The image stacks were fused subsequently with the freely available software CombineZM or ZP. The fused images were stitched to panoramas with Adobe Photoshop CS 3 (for details on these imaging methods, see, e.g. Haug J.T. et al. 2008, Haug C. et al. 2009, Kerp \& Bomfleur 2011).

Additionally, stereo images were taken to receive information on the three-dimensional structures of the specimen. For this purpose, the camera was moved by some degree left and right. The resulting images were assembled as red-cyan stereo anaglyphs in Adobe Photoshop CS 3 (Haug C. et al. 2012a).

For enhancing the contrast between structures of the specimen and the surrounding matrix, autofluorescence imaging was used (Haug J.T. et al. 2011). For this purpose, cyan filters were placed in front of torches, which were used to illuminate the specimen. To only record the fluorescence light emitted by the specimen, a corresponding red filter was placed in front of the camera lens (Haug C. et al. 2012a).

Evaluating functional units. - Lamsdell (2013) (re-) introduced a distinct differentiation between tagmata and pseudotagmata (see also references therein and older concept of Hammen 1963, 1980; Dunlop \& Lamsdell 2017). According to this concept, only the differentiation of appendages provides information about true tagmata. Other structural characters such as sclerites would not provide information about tagmata; units indicated by these characters were termed pseudotagmata. The latter can, according to Lamsdell (2013), be further differentiated into functional and non-functional pseudotagmata.

We disagree on these aspects. It appears to us that the differentiation into tagmata and pseudotagmata as well as into functional and non-functional pseudotagmata is largely based on a partly subjective evaluation of the functionality of characters. For example, changes in the division of sclerites can have an important functional basis, even without changes in the appendages. Evolutionarily speaking, such changes usually do not occur without any reason: Either there should be a direct benefit for the animal, or the change might be linked to another change and does not have negative effects.

Therefore, we used an alternative approach to identify tagmata in this study. As Haug C. et al. (2012b) have put 
forward, information from appendages as well as that from sclerites (individual morphology and conjoined areas of several sclerites) and the spatial arrangement can be taken into account for identifying tagmata. The criteria identified by Haug C. et al. (2012b) are: 1) dorsally or ventrally conjoined segments (e.g. shield); 2) similar dorsal morphology (mostly tergites); 3 ) similar appendage morphology (implying similar function) or related function (but differing morphology, e.g. mouthparts); 4) close spatial association of segments versus long distance to other segments. Ideally, several of these four criteria coincide and characterise a distinct tagma.

Reconstruction approach. - For reconstructing the ground pattern states of tagmosis for the different nodes in Euchelicerata and to understand the evolution leading to these, we follow the concepts of phylogenetic systematics in the sense of Hennig (1966; see also Ax 1995). To achieve a proper character polarisation, outgroup comparisons are included.

As phylogeny and character reconstruction is a reciprocal process (reciprocal illumination sensu Hennig 1966) it is often difficult to present such a reconstruction in a way that the reader can easily follow. Reif (2002) described the overall process as a hermeneutical spiral. As text per se allows only a linear presentation of an argumentation, we can only enter the spiral at a certain point and "follow the winding", i.e. discuss the coherence of the presented reconstruction. With this strategy, the character reconstruction should be comprehensive. In being optimised for coherence and comprehensibility, the presentation follows strict scientific concepts as far as possible (see also Assis 2009), given the unavoidable uncertainties which are outlined as well in the following.

\section{Reconstruction}

In the following paragraphs we will outline the tagmosis of the various stem species in the lineage towards Euchelicerata as well as in the basal branchings of the group up to modern scorpions (Scorpiones).

\section{Megacheira}

Not everybody agrees on the position of megacheiran arthropods within the phylogenetic framework of Euarthropoda: Megacheira has been interpreted as a group inside Euarthropoda and branching off the evolutionary lineage towards Euchelicerata (Chen et al. 2004, Maas et al. 2004, Haug J.T. et al. 2012a, Edgecombe \& Legg 2014 in fact consequently making Chelicerata s.str. = Euchelicerata + Pycnogonida an ingroup of Megacheira).
An alternative interpretation sees megacheirans closely related to, but outside Euarthropoda and not necessarily as monophyletic (e.g. Legg 2013, which could be read in a way that Euarthropoda is an ingroup of Megacheira).

For both interpretations, the principle organisation of a well-known megacheiran species, such as Yohoia tenuis (Haug J.T. et al. 2012a) or Leanchoilia superlata (Haug J.T. et al. 2012b) can serve as an 'evolutionary starting point' for understanding the evolution of modernday cheliceratan groups in representing a type of body organisation close to the ground pattern of Euarthropoda (Fig. 1). The first post-ocular segment bears a pair of prominent grasping appendages that is structurally quite similar to many modern-day chelicerae (Haug J.T. et al. 2012a) on the exact same body segment. The following segments (mostly about 14, but depending on the species) each bear a pair of sub-similar appendages ventrally. All these appendages consist of a large basipod with a median spine-bearing 'blade'. (Note that the basipod is often called "coxa" in different cheliceratans, although the most proximal appendage element is evolutionarily a basipod like in other euarthropods; for better correlation between different groups, we use basipod here.) Medio-distally the basipod carries the endopod that consists of about 7 (sometimes up to 9) tubular elements with disto-median spines. Latero-distally, on an angled edge, the basipod carries a paddle-shape exopod. Proximal parts of endopod and exopod may form a specific joint (Liu et al. 2007, Haug J.T. et al. 2012b). The leg-bearing segments do not seem to have distinct sternitic sclerotisations.

Dorsally, the ocular segment and post-ocular segments 1-4 form a distinct head shield, the following segments have separate, similar-looking tergites. The very posterior segments may lack appendages; then these segments form 'ring' segments, i.e. the ventral side is sclerotised and continuous with the tergite (as for example in Yohoia tenuis, Haug J.T. et al. 2012a). The principle tagmosis, a separation into head and trunk, is therefore largely recognisable based on differences in the dorsal sclerotisations. There are only two tagmata in the ground pattern of Megacheira, the head and the trunk (Fig. 1). Both are involved in feeding and locomotion.

\section{Chelicerata s.str. (Pycnogonida + Euchelicerata)}

The exact ground pattern of Chelicerata s.str. is partly difficult to assess. This is strongly influenced by difficulties with the one daughter group, Pycnogonida, the group of sea spiders. Sea spiders bear a pair of chelicerae on the first post-ocular segment (the idea that these appendages arise from the ocular segment has largely been discarded; Jager et al. 2006, Manuel et al. 2006). 
Although often termed cheliphora, this appendage and its principle organisation is best understood as having a single evolutionary origin with the chelicera (some details on this aspect in Haug J.T. et al. 2012a; see also Dunlop \& Arango 2005, Brenneis et al. 2008, Dunlop 2010). Postocular segments 2-7 bear appendages in most extant species, although appendages of post-ocular segments 2 and 3 (and also of post-ocular segment 1) may be reduced in different species (e.g. Arango 2002). More posterior segments are very small and not separated from each other in modern species. In some fossil species these segments are more prominent and separately visible, but seem to lack appendages (e.g. Bergström et al. 1980, Poschmann $\&$ Dunlop 2006). Some deeper ingroups of Pycnogonida (e.g. Hedgpeth 1947, and at least one fossil species from the Devonian: Kühl et al. 2013) have additional segments with appendages, but this has been generally interpreted as secondarily evolved, not representing a ground pattern feature (e.g. Arango \& Wheeler 2007).

What makes the evaluation of the tagmosis now difficult is that the posterior segments of the fossil forms do not have appendages at all. We therefore simply do not know whether in the ground pattern of Chelicerata sensu stricto there is a specialisation, i.e. differentiation between the appendages of post-ocular segments $2-7$ and those of the more posterior ones (as we will discuss further below for eucheliceratans). Through the presence of appendages on these segments in eucheliceratan species we need to assume the presence of such appendages in the ground pattern of Chelicerata sensu stricto, but we cannot reconstruct their morphology.

The appendages of pycnogonids themselves are quite different from those of megacheirans, most obviously they lack an exopod. It is therefore not possible to determine correspondence of appendage sub-structures of sea spiders with those of eucheliceratan species so far. Dorsally sea spiders retain the condition of megacheirans, ocular segment and post-ocular segments 1-4 form a shield (combining these segments to a tagma often called 'cephalosoma'), all further posterior segments have free tergites.

Based on the observed pattern, the characterising autapomorphy for the node of Chelicerata s.str. is the morphology of the pair of appendages of the first postocular segment, which is each composed of a peduncle with two elements (plesiomorphy) and a distal claw made up of only two elements (apomorphy). Plesiomorphically, this appendage consisted of more elements, the distal part forming a multichela (Haug J.T. et al. 2012a). This holds also true for evolutionary reconstructions that do not see megacheirans in the direct lineage towards Chelicerata s.str. It needs to be pointed out that a distinction into a prosoma and opisthosoma cannot be easily assumed at the evolutionary level of Chelicerata s.str. It is possible that the principle tagmosis still resembles that of megacheiran species: 1) the functional head is formed by the ocular segment and post-ocular segments 1-4 indicated by the head shield; 2) the trunk is formed by all remaining segments with free, similar-looking tergites. At least postocular segments 1-13 bore appendages (partly inferred from data on Euchelicerata, see below), possibly more. There might have been no differentiation between the post-ocular appendages $2-13$. Consequently, it makes also no sense to apply the concept of a prosoma-opisthosoma boundary for representatives of Pycnogonida (see also Vilpoux \& Waloszek 2003).

\section{Euchelicerata}

The monophyletic group Euchelicerata is often treated as representing the most inclusive group with extant representatives ("crown group"; note that the preciseness of the term "crown group" has been tremendously weakened, see Donoghue 2005; it is meant here in the sense as explained at the beginning of this sentence). Yet, it seems that some fossil species that have often been treated as ingroups of Xiphosura are in fact branching off before the "crown group" (Lamsdell 2016). Still, these are generally considered as representatives of Euchelicerata (e.g. Lamsdell 2013). Of most of these species the morphology, especially that of the appendages, is not sufficiently preserved for this analysis (Legrandella lombardii: Eldredge 1974; Anderella parva: Moore et al. 2007; Camanchia grovensis: Moore et al. 2011; Venustulus waukashensis: Moore et al. 2005a). Hence, in the following we will discuss three species with a rather well preserved morphology, namely Weinbergina opitzi, Offacolus kingi and Dibasterium durgae. All three species exhibit a quite differentiated body organisation compared to the nodes before:

1) There appears to be no doubt that in all three species the appendages on the first post-ocular segment represent the chelicerae. All of them have prominent appendages on post-ocular segments $2-6$, yet their structure is known to different degrees of detail. In all three species an endopod consisting of tubular elements has been recognised. Additionally, exopods are present obviously in O. kingi (Sutton et al. 2002) and D. durgae (Briggs et al. 2012). A prominent basipod seems to be present in W. opitzi (Stürmer \& Bergström 1981, Moore et al. 2005b), but has not been reconstructed in the other two species. An independent insertion of an endopod and exopod into the body has been proposed for these, i.e. without a basipod (Briggs et al. 2012). Yet, we presume that this is much more likely a matter of preservation or coupled to the method of reconstruction, which 


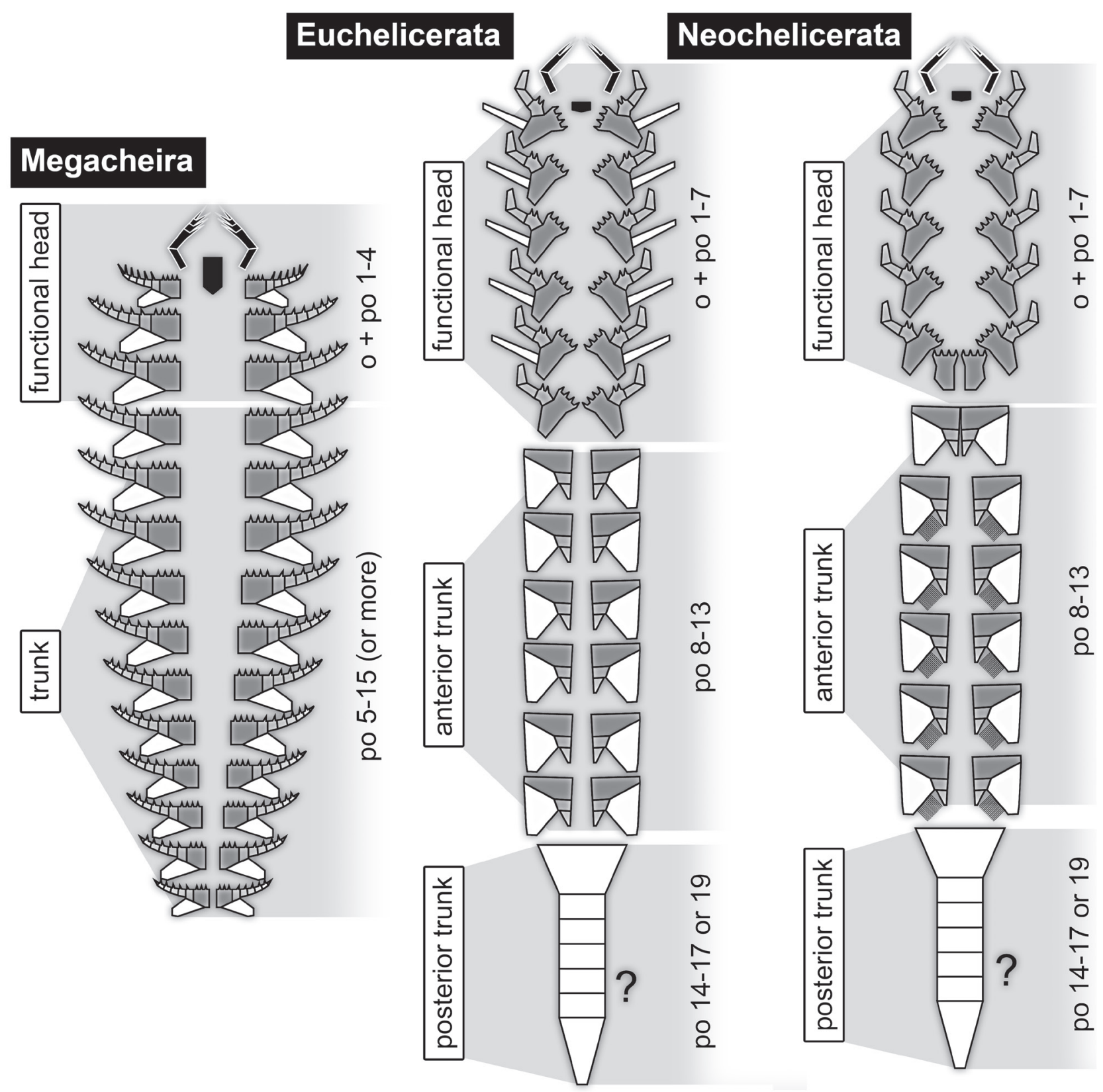

Figure 1. Tagmosis in the ground pattern of Megacheira, Euchelicerata and Neochelicerata with appendage differentiation for each segment. Grey background shadings mark different tagmata. Colour coding: black = appendages of first post-ocular segment (great appendages resp. chelicerae) and hypostome ("labrum"); dark grey = basipod; light grey = endopod; white = exopod and (possibly) limbless segments. Presence of specific respiratory structures not known for the ground patterns of Megacheira and Euchelicerata. Abbreviations: o - ocular segment; po - post-ocular segment.

may not provide a sufficiently high resolution towards the proximal region of the appendages. Unfortunately, especially the attachments of the appendages to the body are not well visible in the image material depicted in Briggs et al. (2012); reinvestigations of the raw image stack previous to reconstruction might provide more information. Regardless of this, the idea that these species are informative about the evolutionary formation of biramous appendages (as for example in Briggs et al.
2012) is highly unlikely, also due to the deep ingroup position within Euarthropoda. The presence of exopods has furthermore been suggested also for $W$. opitzi (Selden et al. 2015, Dunlop \& Lamsdell 2017). The presence of exopods on appendages of post-ocular segments 2-6 is also a major argument that these three species are outside the "crown group" (contra e.g. Briggs et al. 2012).

The appendages of post-ocular segment 7 in $W$. opitzi appear to consist of a basipod and an endopod resembling 
those of the further anterior appendages (Lehmann 1956, Stürmer \& Bergström 1981, Moore et al. 2005b, but see also discussion in Selden et al. 2015). In the other two species an endopod seems to be absent on this appendage. Interestingly, in $O$. king $i$ the appendages of post-ocular segment 7 are flap-like and look more similar to the further posterior appendages than to the anterior ones (Sutton et al. 2002). Still, these appendages appear to close the feeding apparatus from posteriorly. Therefore, we can recognise a distinct functional unit ventrally: the ocular segment and post-ocular segments 1-7 form the feeding apparatus (Fig. 1).

This functional unit seems to be also represented on the dorsal side. The large shield is formed by the same segments. It remains unclear why there is the persisting idea that post-ocular segment 7 possesses a separate tergite (see, for example, discussion in Haug C. et al. 2012a on the idea of a "microtergite" and further below in paragraph "Metastomata"). A small structure, supposed to be a tergite, has been reconstructed on this segment in D. durgae. Yet, it differs from the further posterior structures representing clear tergites. The small structure may as well be interpreted as a more prominent membraneous area; also the exact segmental correlation of the appendages and tergites seems challenging in the fossil (Briggs et al. 2012). In $O$. kingi, post-ocular segment 7 has been interpreted as contributing to the head shield (Sutton et al. 2002). For W. opitzi the condition seems unclear (Dunlop $\&$ Lamsdell 2017). Also in modern xiphosurids there is no hint for a separate tergite of post-ocular segment 7 . Together with the fact that the appendages of postocular segment 7 are in xiphosurids and probably in all three species discussed here clearly incorporated into the feeding apparatus, no reliable indication for interpreting this segment as not contributing to the head shield is left.

For the ground pattern state of Euchelicerata the most anterior tagma can therefore be recognised by: a) similar functionality of the appendages; b) close spatial association of these appendages; c) dorsally conjoined segments.

This tagma can be considered a functional head, as it is usually the case for the first distinct tagma dorsally forming a shield. Scholtz \& Edgecombe (2006) have argued otherwise, yet their criterion that a head should not be locomotory in function would mean that a lot of arthropodan species could not possess a head, e.g. water fleas (cladoceran crustaceans), which swim with their antennae (appendages of the second post-ocular segment). In consequence, we consider 'functional head' as an appropriate term for this tagma.

2) The post-ocular segments $8-13$ differ significantly from the further anterior and posterior segments, but resemble each other in several aspects. The appendages of these segments are paddle-like, basipod and exopod are large, the endopod is rather small or appears to be absent (Sutton et al. 2002). These appendages are not involved in feeding, but appear to be swimming appendages. Dorsally, each segment forms a distinct sclerotic tergite. All six pairs of appendages appear very similar in the fossils and show no further differentiation.

For the ground pattern state of Euchelicerata the second tagma can therefore be recognised by: a) similar morphology and functionality of the appendages; b) close spatial association of these appendages; c) dorsally similar appearing segments with free tergites.

For similar tagmata there are several names available within Euchelicerata, examples of which are mentioned in the following. For $O$. kingi the term mesosoma has been used for this tagma (Sutton et al. 2002); also in scorpions a comparable tagma, but not exactly matching concerning segments, is generally termed mesosoma. For $D$. durgae and other groups, especially fossil ones, the tagma behind the head has been termed pre-abdomen (e.g. Eldredge 1974, Briggs et al. 2012). Yet, this is a bit unfavourable as it indicates that there is a true abdomen in these groups, which is not the case (the same problem of ambiguous terminology occurs also, for example, in Insecta; see also discussion on the term 'abdomen' in Walossek \& Müller 1998). For simplicity, and without implying connection to existing special terms, we refer to the second tagma as the 'anterior trunk'.

3) The further posterior segments are distinct from the further anterior segments. They lack appendages. Postocular segment 14 seems to possess a separate tergite and sternite (though for D. durgae it is only mentioned that this segment bears no appendages, but nothing is stated about the presence or absence of a sternite; Briggs et al. 2012, Dunlop \& Lamsdell 2017). The further posterior segments are sub-similar to each other in forming ring segments, without a separate tergite and sternite, at least in D. durgae and $W$. opitzi where three such segments are present (Moore et al. 2005b, Briggs et al. 2012, Dunlop \& Lamsdell 2017); for $O$. kingi no such ring segments have been described (Sutton et al. 2002, Dunlop \& Lamsdell 2017), but the resolution of preservation in this area is relatively poor.

It is unclear how many of these segments were in the ground pattern of Euchelicerata. The exact number of trunk segments (= all segments posterior to the functional head) in early megacheiran species seems highly variable and can reach more than 20 (e.g. Jianfengia multisegmentalis; Chen et al. 2004). Traditionally, it has been believed that there should be 19 post-ocular segments in Euchelicerata (e.g. Weygoldt \& Paulus 1979), which would result in 12 trunk segments (contra Weygoldt \& Paulus 1979 who stated that the anterior tagma has only 
6 post-ocular segments). There seem to be fewer in the three species discussed here, namely maximally 10 . Only four segments posterior to the anterior trunk are apparent in the fossils, even fewer seem to be present in modern xiphosurids based on data from musculature and nervous system (e.g. Scholl 1977, figs 5, 13; Shultz 2001, fig. 1a). It may therefore be possible that a rather low number of segments was present at this evolutionary level.

A further question arising is where the ventral sclerotisations originate from. Xiphosurids do not appear to have a pronounced sternite system on the appendage-bearing segments. This seems to be the case for megacheirans as well. A possible mechanism for the origin of newly appearing sternitic plates will be discussed further below.

For the ground pattern state of Euchelicerata (Fig. 1) a third tagma can therefore be recognised by segments being subsimilar in: a) absence of appendages (which can be interpreted as a similar appendage morphology in the wider sense); b) an extensive ventral sclerotisation, which is on the first segment a free sternite, but conjoined to the tergite to form ring segments in the further posterior segments. The latter criterion has not been listed in Haug C. et al. (2012b), but seems to be appropriate for this case. Furthermore, it might not be an independent character as the sternitic sclerotisations might indeed represent derived appendages (see discussion further below). This third tagma is largely characterised by a lack of characters, which seems, to our impression, to be often the case in the most posterior tagma, representing something like a "left over".

As above, in the fossil species described here as well as for a comparable tagma in extant groups (e.g. in scorpions) names such as metasoma or post-abdomen were used. To avoid any confusion, we refer to this tagma as 'posterior trunk'.

Summarising, the (reconstructed) stem species of Euchelicerata is characterised by a distinct new tagmosis. There are three distinct functional units: 1) a functional head including the ocular segment and post-ocular segments $2-7 ; 2)$ the anterior trunk including post-ocular segments $8-13 ; 3)$ the posterior trunk including post-ocular segments 14-17 or 14-19 (Fig. 1).

The tagmosis of the the stem species of Euchelicerata as reconstructed here is in consequence not coherent with the traditional prosoma-opisthosoma organisation. The transition between first and second tagma is between post-ocular segments 7 and 8 while that between prosoma and opisthosoma is thought to be between post-ocular segments 6 and 7 (e.g. Dunlop \& Lamsdell 2017). Also the trunk subdivision does not correspond to the traditional mesosoma-metasoma border which should be between post-ocular segment 14 and 15 (e.g. Dunlop \& Lamsdell 2017), while the transition between anterior and posterior trunk is between post-ocular segments 13 and 14 .

\section{Neochelicerata}

This group equals the "crown group" (in Lamsdell 2016, fig. 1, everything above the split off of Legrandella lombardii). The stem species possesses distinct specialisations absent at the node of Euchelicerata. Yet, some of these might have evolved some nodes further below Neochelicerata, as the three fossil species discussed above for Euchelicerata show some of these to a certain degree.

1) Appendages of post-ocular segments $1-7$ are still contributing to the feeding apparatus as seen in xiphosurids and eurypterids, i.e. they are tightly incorporated into the functional head. All of these appendages have lost the exopods. It should be mentioned that the flabellum, a structure on the appendages of post-ocular segment 6 , is sometimes interpreted as an exopod (e.g. Walossek \& Müller 1998, Dunlop \& Lamsdell 2017), yet might possibly represent an exite (Wolff \& Scholtz 2008). This further differentiates these appendages from those of the anterior trunk which have well-developed exopods. The appendage of post-ocular segment 7 (chilaria in xiphosurids and possibly already in Venustulus waukashensis, see Moore et al. 2005a, fig. $3.3+3.4$; metastoma in eurypterids) has lost its endopod as well. In this aspect, it differs to some degree from the other appendages, yet it is now even closer spatially associated with the other segments of the functional head as it is squeezed between the appendages of post-ocular segment 6 , and it also contributes to the feeding apparatus by closing it from posteriorly. As for the nodes before, there is no unequivocal indication of a tergite corresponding to postocular segment 7 (Fig. 1; see discussion on the microtergite in Haug C. et al. 2012a and references therein).

2) Appendages of post-ocular segments $8-13$ are still paddle-like. They are still used in swimming. As the anterior appendages now lack exopods, swimming is exclusively performed by the appendages of post-ocular segments $8-13$. Yet, the series is differentiated to a certain degree: the backside of appendages of post-ocular segments 9-13 additionally carries book gills (Fig. 1). It is important to note for further discussion, that these appendages are not book gills, but carry them. The pair of appendages of post-ocular segment 8 largely resembles the further posterior ones, but does not carry book gills. It acts as a functional lid for the gill chamber and the genital openings as well. For Dibasterium durgae a similar morphology of the appendages of post-ocular segments 8-13 has been presumed (Briggs et al. 2012).

3) Further posterior segments lack appendages. Also all besides the first one (post-ocular segment 14) still seem 
to form ring segments; more precisely, tergite and sternite are laterally conjoined though without resulting in a ringshaped segment.

The appendage of the last segment of the first tagma (functional head, post-ocular segment 7) and the most anterior one of the second tagma (anterior trunk, postocular segment 8 ) have become slightly differentiated from the other appendages of their tagmata. Still, their close morphological and functional similarity as well as the close association to the other appendages is apparent.

Therefore, the principle tagmosis is unchanged compared to Euchelicerata (Fig. 1). There is still no correspondence to the traditional prosoma-opisthosoma or mesosoma-metasoma boundary.

\section{Metastomata (Eurypterida s.l. + Arachnida)}

The representatives of Eurypterida s.l. (especially of Eurypterida s.str. (sea scorpions), i.e. without Chasmataspidida, see Shultz 2007a) demonstrate an important intermediate step towards modern day arachnid cheliceratan species (see e.g. Garwood \& Dunlop 2014, Lamsdell 2016). A major novelty that seems to be autapomorphic for Metastomata is the reduced movability of the basipods. More precisely for each tagma separately:

1) Xiphosurids can move the basipod against the body in anterior appendages (those of post-ocular segments 2-7) as well as posterior ones (those of post-ocular segments $8-13)$. In sea scorpions the movability of the basipods of appendages of post-ocular segments 2-6 appears to be reduced. Most movements seem to have been performed at the basipod-endopod joint, while plesiomorphically the main joint for moving the appendages was the bodybasipod joint.

The appendages of post-ocular segment 7 have become conjoined and form a single structure, the metastoma, possibly without the ability to move (Fig. 2). In how far the conjoined state is present in the ground pattern is partly unclear. There are eurypterids that still possess a deep cleft in their metastoma (see Tollerton 1989 for a summary of different shape of eurypterid metastomata). Similarly, in early fossil scorpions the sternum (the presumably corresponding structure) also possesses a deep cleft or furrow (e.g. Waddington et al. 2015; partly also in modern scorpions, see Soleglad \& Fet 2003); in some specimens of Scorpionida one could even get the impression that they are not conjoined at all (see further below). It seems therefore possible that a proximally conjoined state with a distal cleft could be part of the ground pattern for Metastomata, yet it remains uncertain.
In the membrane between anterior dorsal shield and tergite of post-ocular segment 8 , a sclerotisation occurs in different representatives of Chasmataspidida and Eurypterida s.str. (e.g. Dunlop \& Webster 1999, Dunlop 2002, Marshall et al. 2014 and references therein). Some authors supposed that this so-called "microtergite" could represent the dorsal identity of post-ocular segment 7 (e.g. Lamsdell 2013, Marshall et al. 2014). However, this sclerotisation does not necessarily imply a segment identity but may also occur in the intersegmental membrane, supported by a generally different morphology of the "microtergite" compared to the next posterior tergite (see extensive discussion in Haug C. et al. 2012a). Therefore, we currently think that it is more parsimonious to assume that the dorsal identity of post-ocular segment 7 , like the ventral one, is incorporated into the first tagma in the ground pattern of Metastomata.

2) The movability of appendages of post-ocular segments $8-13$ is likewise hardly present. The exact condition for the appendage of post-ocular segment 8 is difficult to reconstruct. Eurypterids have prominent external genital appendages, while arachnids have only simple opercula. It might well be that the prominent eurypterid type appendage is a specialisation of this lineage and not part of the ground pattern.

The book gills on the posterior side of the appendages of post-ocular segments 9-13 are now recessed below functional lids (e.g. Waterston 1975 reported the occurrence of gill tracts with possible respiratory function; Braddy et al. 1999 proposed the presence of lamellate book gills). As in xiphosurids the gills are on the backsides of the exopods, it seems likely that the functional lids are indeed formed by former basipod and exopod, without expressing a subdivision.

3) Further posterior segments remain principally unchanged. They lack appendages, and all but the first one form ring segments. Similar to the appendages further in front, the sternitic sclerotisations of these segments could represent remains of appendages that have become functional sternites. At least this should be considered a realistic possibility. Furthermore, from here on there should be post-ocular segments 14-19 for sure (Fig. 2).

The principle tagmosis has remained the same in the ground pattern of Metastomata. Appendage of postocular segment 7 is still strongly incorporated into the feeding apparatus, but differs now even more from the further anterior appendages, by being conjoined medially. Also appendage of post-ocular segment 8 is more different from the further posterior appendages, by possibly retaining external parts, not entirely appearing plate-like or sternite-like. 
Metastomata

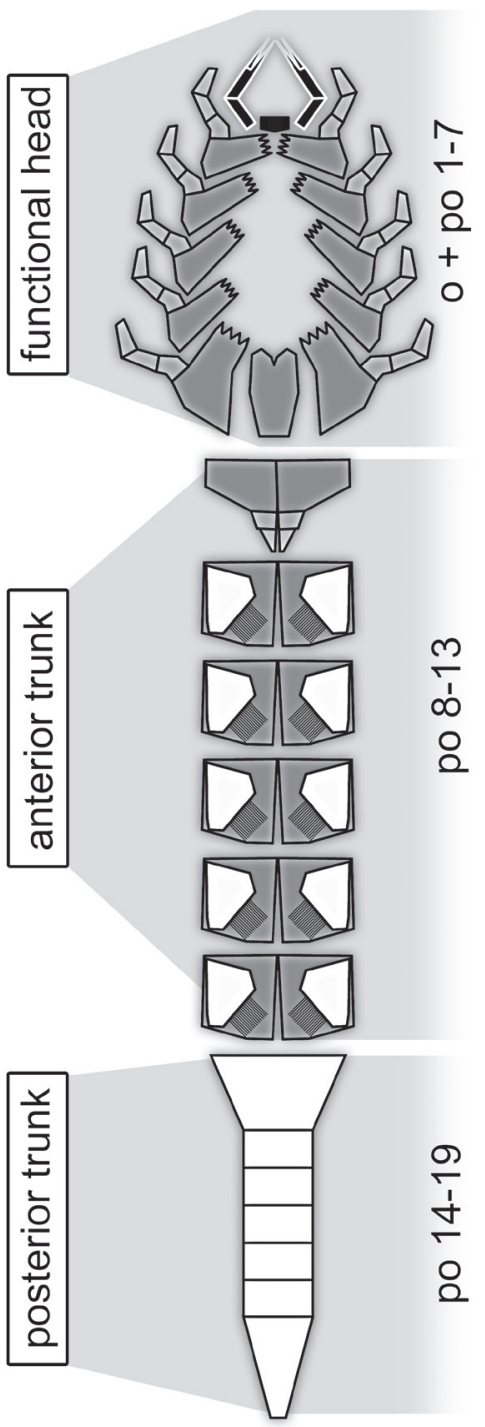

Scorpionida
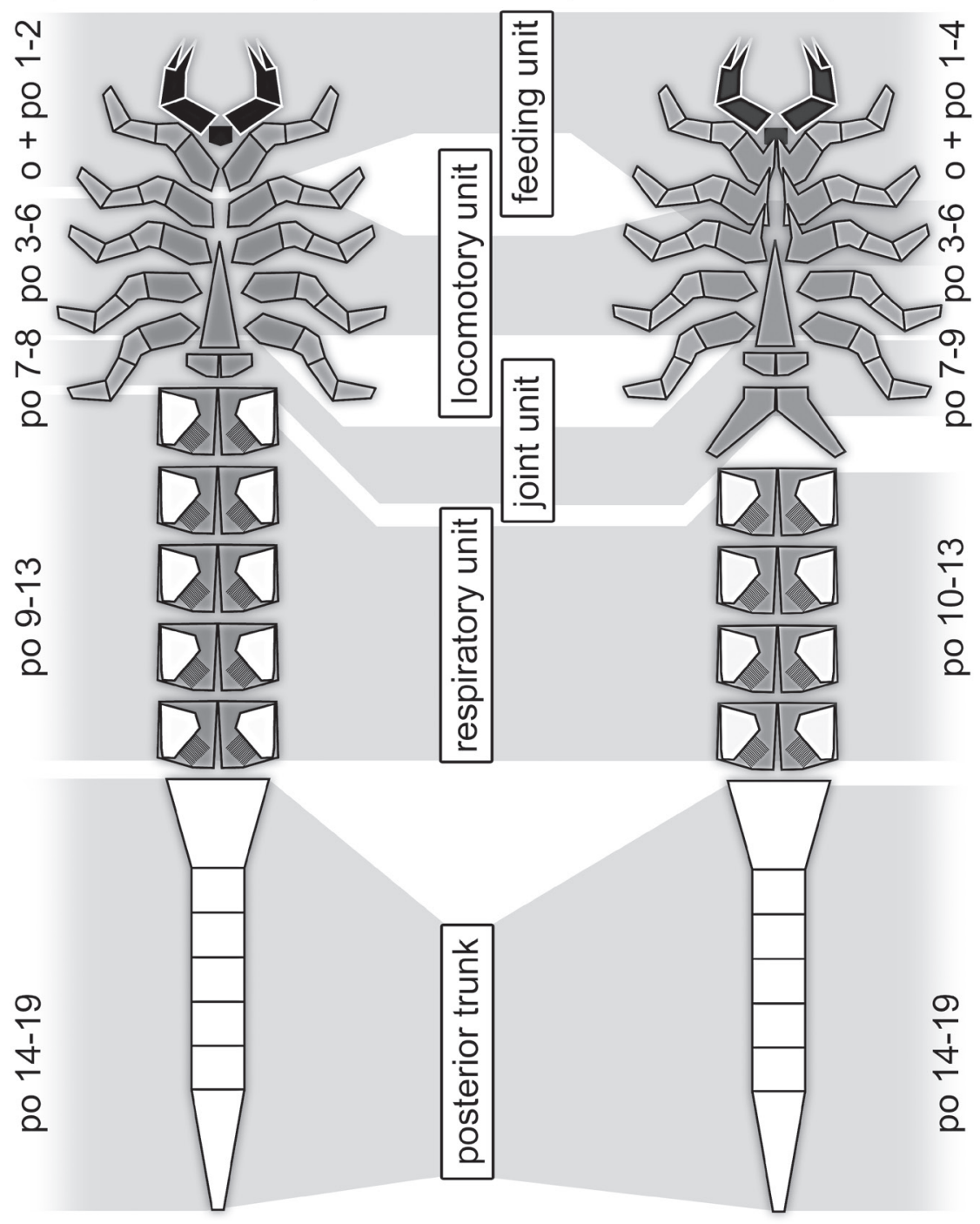

Scorpiones

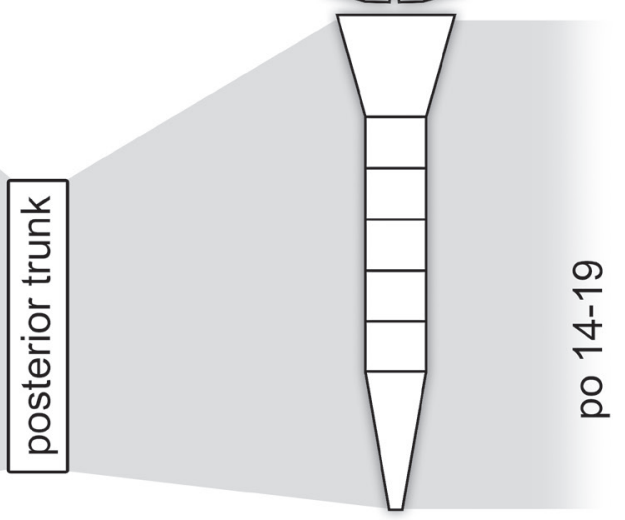

Figure 2. Tagmosis in the ground pattern of Metastomata, Scorpionida and Scorpiones with appendage differentiation for each segment. Grey background shadings mark different tagmata. Colour coding: black = appendages of first post-ocular segment (chelicerae) and hypostome ("labrum"); dark grey $=$ basipod; light grey $=$ endopod; white $=$ exopod and (possibly) limbless segments. Abbreviations: o - ocular segment; po - post-ocular segment.

\section{Arachnida}

The phylogenetic relationships within Arachnida are far from well understood. As the focus is here mostly on scorpions, we only briefly involve other arachnids where necessary, but else-wise cut the discussion short for simplicity. As an important comment: Currently, many phylogenetic reconstructions resolve scorpions deeply within Arachnida (see discussion in Giribet 2018 and references therein; in a very recent study even Xiphosura results as ingroup of Arachnida: Ballesteros \& Sharma 2019 ) instead of being in a sister group relationship to
Lipoctena (i.e. the remaining groups within Arachnida) as suggested, for example, by Weygoldt \& Paulus (1979). This is especially the case in molecular and morphological reconstructions that do not involve Eurypterida s.l. Without this group, Arachnida lacks an important polariser. Hence we see it as likely that the deep ingroup position of scorpions is an artefact caused by the lack of proper character polarisation. In the following, we consider the position of Scorpionida as a sister group to Lipoctena as the more likely one, yet the exact relationships do not further influence the discussion; also a sister group relationship of Scorpionida with Megoperculata (as favoured in recent 
studies, e.g. Sharma et al. 2014a, Klußmann-Fricke \& Wirkner 2016) would not influence it.

In the ground pattern of Arachnida, the immobilisation of the basipods has reached a peak. For the individual tagmata this means:

1) The basipods are broadly attached to the body wall in post-ocular appendages $2-6$, forming functional sternitic anchors for the distal part of the appendage (endopod). The feeding function is no longer performed, at least by the post-ocular appendages 5-7. The exact condition for the further anterior appendages is more difficult to evaluate and needs to be dealt intensively in a separate reconstruction focusing on the feeding apparatus.

Appendages of post-ocular segment 7 are very indistinct. Some authors have suggested that they disappear during the embryonic phase (e.g. Dunlop 1998, fig. 4). Yet it seems that they form a single sternitic plate, the sternum (corresponding to the sternum in scorpions, see below, but probably not corresponding to the sternitic plate called sternum in different other groups of Arachnida; e.g. Dunlop \& Webster 1999, Farley 2005).

While it might sound counterintuitive that appendages form a sternitic sclerotisation, this should in fact not be surprising. The distal parts of these appendages have been lost already at the node of Euchelicerata, only the basipod remained. The two basipods have possibly become partly conjoined at the node of Metastomata and already largely immobilised there. As all further anterior basipods, as well as the further posterior ones (see below) have become functional sternitic structures, it seems only consequent that the same accounts for the appendages of post-ocular segment 7.

Structurally, the similarity between the appendages of post-ocular segment 7 and the further anterior ones is not simple to evaluate. Nevertheless, the incorporation of post-ocular segment 7 into the functional head is still indicated by the close association, the sternum is directly surrounded by the basipods of the appendages of at least post-ocular segments 5 and 6 . Also there is no indication that there is a corresponding separate tergite of post-ocular segment 7 , hence dorsally the segment is best understood as still contributing to the shield.

2) The anterior trunk, post-ocular segments $8-13$, share with the first anterior segments that the basipods have become further immobilised. All form in principle one sternitic plate per segment, possibly a pair in post-ocular segment 8 . Post-ocular segment 8 carries the genital opening, the following five most likely each carried a pair of book lungs, although we do not have a modern representative with such a condition.

3) The posterior trunk, post-ocular segments 14-19, remains unchanged compared to the ground pattern of Metastomata.

The tagmosis of Arachnida is different from that of Metastomata in some aspects: The functional head is now differentiated into an anterior tagma (unclear how many segments exactly) with the function of feeding and locomotion, and a posterior one exclusively with locomotion (at least post-ocular segments 5-6). Based on dorsal aspects, post-ocular segment 7 still dorsally contributes to the shield, at least we have no indication for the opposite interpretation. Ventrally, the appendages of this segment are clearly no longer coupled to the function of the further anterior segments. Therefore, it remains unclear how to interpret the ventral side of these segments. The further posterior tagmata seem to remain unchanged. There is still an anterior trunk and a posterior trunk.

\section{Scorpionida (Scorpiones + fossil relatives)}

The ground pattern of Scorpionida is highly depending on the interpretation of the early fossil representatives of the group, which still differ in quite some aspects from their modern relatives.

1) The early representatives of Scorpionida have a very short feeding apparatus (e.g. Kjellesvig-Waering 1986, Waddington et al. 2015). Only chelicerae and pedipalps are involved in feeding, and of course the hypostome or "labrum" arising from the ocular segment. Hence, the first functional unit, the feeding unit, includes the ocular segment and post-ocular segments 1-2 (Fig. 2). This is based on a) similar function and b) close spatial association.

2) Appendages of post-ocular segments 3-6 are exclusively locomotory in function. The second functional unit therefore includes these segments (Fig. 2). This is based on similar appendage morphology of these segments.

Dorsally, functional units 1 and 2 form the shield. Also post-ocular segment 7 still seems to contribute to the shield, not possessing a separate tergite.

3) The ventral side of post-ocular segment 7 is difficult to understand, comparable to the state in the ground pattern of Arachnida. Understanding the condition in Scorpionida might indeed provide a crucial distal polarisation for Arachnida in this aspect.

There has been quite some debate whether the sternum in scorpions is a derivative of the appendage pair of postocular segment 7 (e.g. Dunlop \& Webster 1999). Farley (2005) argued, based on embryological data, that the 

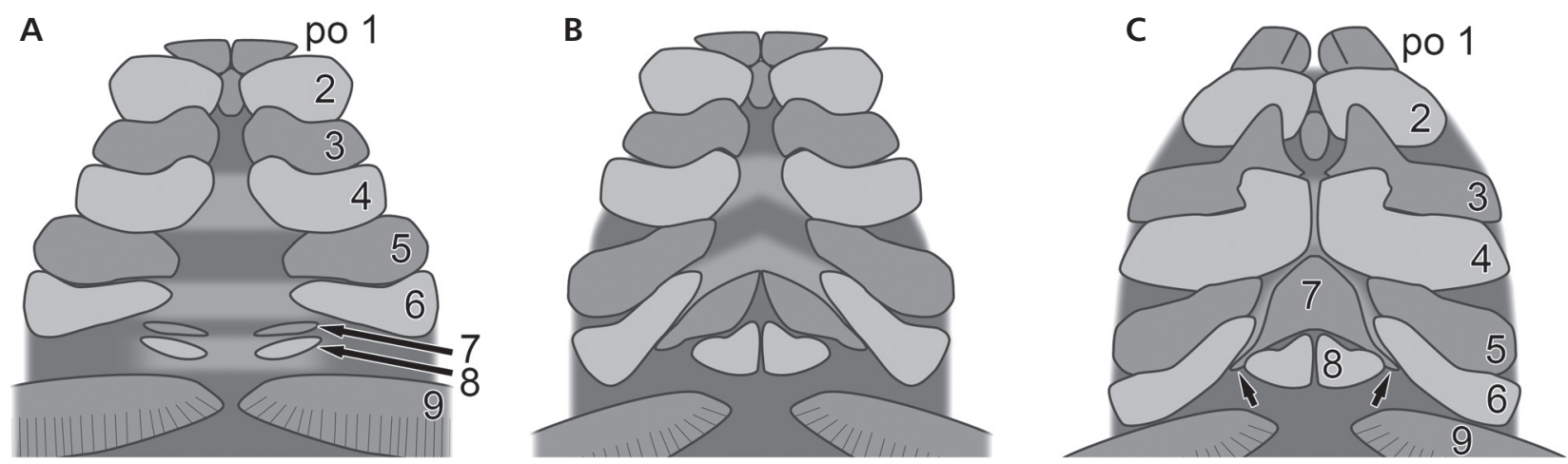

Figure 3. Developmental changes on the ventral side of the anterior body region in modern scorpions, based on embryological data (modified after Farley 2005). • A - early embryo with segments and associated appendage anlagen forming more or less well recognisable straight bars; post-ocular segment 7 quite short in anterior-posterior axis with a pair of small elevations, the presumed appendage anlagen of this segment (Farley 2005, fig. 2). • $\mathrm{B}$ - later stage than A; median parts of appendage anlagen moved forward during embryonic development; post-ocular segment 7 becomes largely V-shaped (Farley 2005, fig. 3). • C - later stage than B; appendage anlagen of post-ocular segment 7 fused and lying between the basipods of the further anterior appendages (Farley 2005, fig. 6). Small arrows pointing at postero-lateral folds of the appendage anlagen of post-ocular segment 7, still indicating the origin of this segment posterior to post-ocular segment 6 . Abbreviation: po 1-9-post-ocular segment 1-9.

sternum is a composite structure (see below). Yet, when looking at Farley's data this interpretation is far from obvious.

What can be observed is that in early embryos of modern scorpions all segments form more or less well recognisable straight bars at first. Post-ocular segment 7 is quite short in anterior-posterior axis. A pair of very slight elevations is apparent, most likely representing the anlagen of the appendages (Fig 3A; Farley 2005, fig. 2). During embryonic development these move forward, and the entire segment becomes largely V-shaped, finally lying between the basipods of the further anterior appendages. Postero-laterally extending folds of the appendage anlagen of post-ocular segment 7 still indicate the origin of this segment posterior to post-ocular segment 6 (Fig. 3B, C; Farley 2005, figs 4, 6). While Farley believes that also parts of the anterior segments contribute to the sternum, we see no clear indications for this assumption. What can be observed is a certain gain in size of the sternum, which could also be understood as allometric growth of the appendage anlagen of post-ocular segment 7.

When taking into account early Palaeozoic fossils, the latter view is further supported. Here the sternum largely resembles the adjacent basipods in shape and overall appearance, being only slightly smaller and conjoined posteriorly, but separated anteriorly (Figs 4, 5). One could of course hypothesise that in early scorpions only the appendage anlagen of post-ocular segment 7 will form the sternum, but in modern scorpions additional segments will add material. Yet it seems much more parsimonious to simply explain the change in shape in correlation with a further anterior position of the sternum in more modern forms. In the fossils, the sternum lies between the basipods of post-ocular segments 5 and 6 , in modern forms as far anterior as the posterior region of the basipods of postocular segment 4.

The fact that the appendage anlagen of post-ocular segment 7 appear to develop rather late in ontogeny in comparison to the other appendages in scorpions is unchanged compared to the condition in xiphosurids (e.g. Haug C. \& Rötzer 2018 and references therein). Interesting in this aspect is the developmental pattern of the appendage anlagen of post-ocular segment 8 . Ancestrally, as for example in xiphosurids, these appear to develop early and are far differentiated when the appendage anlagen of post-ocular segment 7 start to develop. In scorpions, both segments seem to follow a very similar pattern concerning timing of development, and more or less also the final morphology as paired sternal structures.

The appendages of post-ocular segment 7 were originally sub-similar to those of the further anterior segments. Those of post-ocular segment 8 were sub-similar to those of the further posterior segments (condition in Neochelicerata). While both differentiated from the further anterior respectively posterior segments, they were still functionally coupled to these (Euchelicerata, Metastomata; partly unclear for Arachnida) and also different from each other.

In the ground pattern of Scorpionida we find a new condition. Post-ocular segment 7 is no longer functionally coupled to the anterior segments. Similarly, the appendages of post-ocular segment 8 differ now from those of the further posterior segments in being smaller than these, differentiating later, and being tucked in between the further anterior segments (see Farley 2005). In all these aspects appendage anlagen of post-ocular segment 7 and 8 are comparable to each other, but differ from the other segments. Also dorsally there is a certain 
difference between post-ocular segment 8 and the further posterior ones, as the tergite of post-ocular segment 8 is shorter in anterior-posterior axis.

We therefore suggest that post-ocular segment 7 (only ventrally) and 8 (full segment) form a new functional unit (Fig. 2). This body region is largely reduced in size (c.f. "pregenital compression", Shultz 2007b). This specialisation is most likely coupled to specific functional needs of the scorpion. Post-ocular segment 7 and 8 have "moved" close to the posterior side of post-ocular segment 6 to internally form a muscular diaphragm (Shultz 2007b). This structure may prohibit too much movement of the inner organs when the sting on the posterior body end is moved anteriorly. Also the small segments help to provide additional joints in this tight space to allow the strong bending of the body. In this way these two segments can be recognised as a tagma by a) similar ventral morphology, b) close spatial association, and c) similar developmental pattern of development. The last criterion is newly introduced here. This tagma functions as a specific joint between the anterior and the posterior body.

4) Post-ocular segments $9-13$ are still sub-similar in carrying book lungs. There has often been the assumption that post-ocular segment 9 should carry pectines also in early fossil representatives of Scorpionida (see, e.g. Kjellesvig-Waering 1986, text-fig. 2; Dunlop 1998; Jeram 1998; Dunlop \& Webster 1999; but see also Dunlop et al. 2008; Poschmann et al. 2008). Yet, reliable support for this assumption remains absent. As an example, the Silurian scorpion Eramoscorpius brucensis (Fig. 6) clearly shows five segments that are sub-similar with paired, roundish, lateral depressions that are, in our view, best interpreted as book lungs. The original authors (Waddington et al. 2015) suggested there could be pectines on the first segment, yet a 3D representation of the surface reveals that this segment is very similar in morphology to the next posterior segment (Fig. 6A, C). There is no indication of comb-like structures or external appendage branches which could point to the presence of pectines in this specimen. The same accounts for other fossil finds of early representatives of Scorpionida (e.g. Dunlop et al. 2008). Also Jeram (1998) noted that some fossil scorpions definitely have five similar mesosomal segments, but is not discussing if this coincides with the lack of pectines. The fossil scorpions that have been supposed to carry pectines (e.g. Vogel \& Durden 1966) can in fact be more easily interpreted as possessing five sub-similar segments carrying book lungs.

There has been the belief that a segment (or parts of it) has been doubled in scorpion evolution (e.g. Weygoldt \& Paulus 1979). This was mainly necessary to account for scorpions carrying pectines and five pairs of book lungs (and for certain data on the musculature). Yet, it seems much more plausible (as being more parsimonious) that early scorpions simply retained five pairs of book lungs and did not yet possess pectines (Fig. 2).

5) Post-ocular segments 14-19 did not change compared to earlier nodes. They are still forming a distinct tagma (Fig. 2).

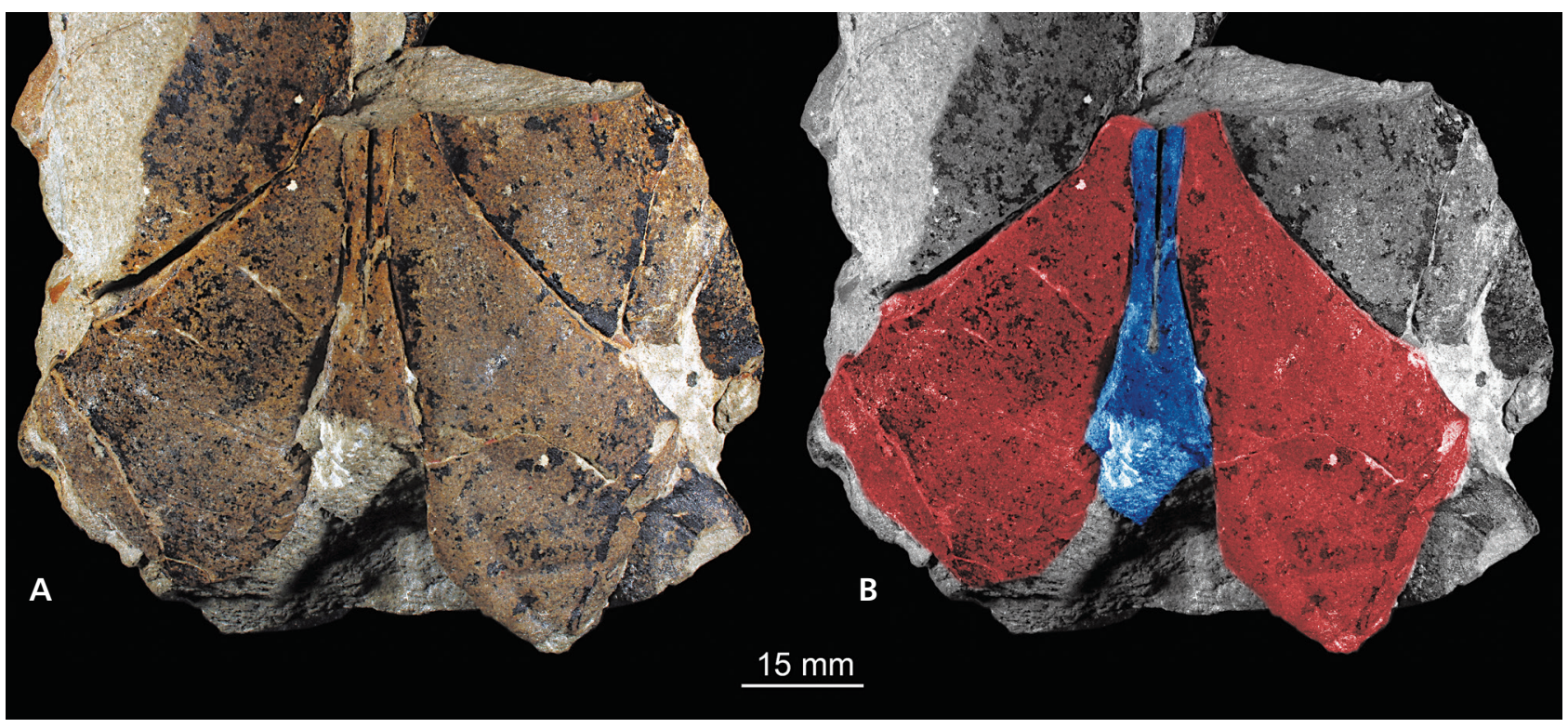

Figure 4. Sternum and surrounding structures of the Lower Devonian scorpion Praearcturus gigas, NHM I534 (In 60444), from Rowlestone, Herefordshire, England. • A - macrophotographic image. • B - same as A, but with colour-marked structures; sternum (blue; post-ocular segment 7) largely resembling the adjacent basipods of walking appendage 4 (red; post-ocular segment 6 ) in shape and overall appearance besides being narrower and conjoined posteriorly, but separated anteriorly. 

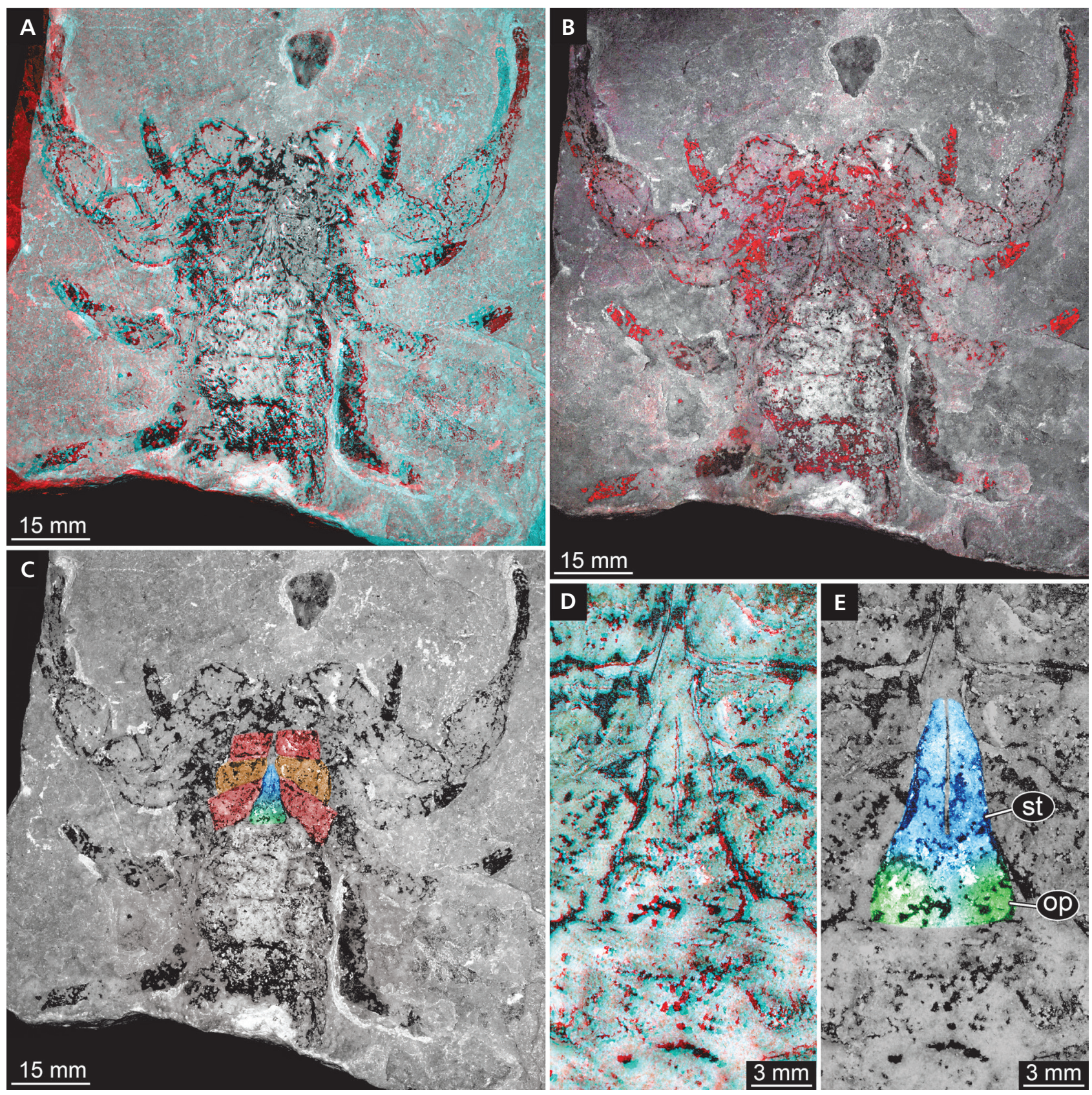

Figure 5. Sternum and surrounding structures of the mid-Silurian scorpion Eramoscorpius brucensis, ROM 53247, from the Eramosa Formation, Canada. $\bullet$ A - stereo image. $\bullet$ B - same as A, but without stereo effect and with colour-marked structures: blue $=$ sternum; green = genital operculum; red, orange $=$ basipods of walking appendages. $\bullet \mathrm{C}$ - macro-fluorescence image. $\bullet \mathrm{D}, \mathrm{E}-$ detail of sternal region; $\mathrm{D}-$ stereo image; $\mathrm{E}-$ same as $\mathrm{D}$, but without stereo effect and with colour-marked structures; sternum (blue; post-ocular segment 7) conjoined posteriorly, but separated anteriorly, followed by genital operculum (green; post-ocular segment 8). Abbreviations: op - genital operculum; st - sternum.

We can therefore recognise five distinct tagmata in Scorpionida (Fig. 2), which result in the following functional units: 1) feeding unit; 2) locomotion unit; 3) joint unit; 4) respiratory unit; 5) posterior trunk. At this node, for the first time a traditional tagma boundary matches with our observations: the anterior two tagmata equal the prosoma, the posterior three equal the opisthosoma. Yet, there is no correspondence to the traditional mesosoma-metasoma boundary. Very interesting in this tagmosis pattern is that the increase in number of tagmata is not only achieved by a subdivision of existing tagmata, but by the de novo formation of a tagma by segments of two different tagmata "uniting". A comparable case was suggested for Pycnogonida (Vilpoux \& Waloszek 2003), yet as outlined above, the case of Pycnogonida is much easier understood as the retention of a plesiomorphic condition. 


\section{Scorpiones (the modern scorpions)}

In modern scorpions, the tagmosis is further derived from the ground pattern of Scorpionida (Fig. 2):

1+2) The clear distinction between the first and second tagma in Scorpionida with ocular segment + post-ocular segments 1 and 2 respectively post-ocular segments $3-6$ is now less clearly expressed, as appendages of post-ocular segments 3 and 4 also contribute to the feeding apparatus (e.g. Snodgrass 1948; also visible in fossil representatives, e.g. Waterstonia airdriensis; Kjellesvig-Waering 1986, text-fig. 99). It seems that enditic structures can well be expressed in embryonic development, although absent in adults, as for example in bird spiders (Pechmann \& Prpic 2009). Based on this observation, also in the ground pattern of Arachnida endites were probably expressed in the embryo and usually reduced in the adult; the same was probably the case in the ground pattern of Scorpionida. In Scorpiones, the endites of the appendages of post-ocular segments 3 and 4 are also expressed in the adult. We can therefore hypothesise that the de novo endites on these appendages represent a kind of reactivation of already present structures.

Modern scorpions seem to possess a mixed tagma corresponding to the prosoma. Yet, in fact there are two overlapping tagmata: a feeding tagma including ocular segment and post-ocular segments $1-4$, and a locomotion tagma including post-ocular segments 3-6 (Fig. 2). Remarkably, the first tagma corresponds to the ancestral head in the ground pattern of Euarthropoda, yet only concerning the secondarily evolved same segmental composition.

3) The joint tagma still includes post-ocular segments 7 and 8 . Yet, now also post-ocular segment 9 resembles these two segments. As post-ocular segments 7 and 8 are now even further anterior than at the node of Scorpionida, also post-ocular segment 9 is now partly recessed into the further anterior segments. Due to this, it is narrower than before and also narrower than the further posterior segments. The ventral side no longer forms a large, more or less continuous sternal plate, but rather separate ones, and from the most posterior one the pectines arise (Fig. 7). It seems most plausible that this segment has been partly influenced by the developmental program of the further anterior segment (see also below). By this, it now closer resembles the further anterior segments, but differs stronger from the further posterior ones. Due to this, we consider it now as part of the third tagma (Fig. 2).

4) The fourth tagma now includes only post-ocular segments 10-13, i.e. it has "lost" the most anterior segment (Fig. 2).
5) Post-ocular segments $14-19$ still form the last tagma (Fig. 2).

\section{General discussion}

What becomes apparent from the investigations above is that exactly pinpointing tagma boundaries in different cheliceratan groups can be rather complicated. One reason for this is that the morphology often exhibits a more or less gradual anterior-posterior shift, especially apparent on the appendages, with the most anterior and the most posterior appendages on the body being very different from each other, while appendages in between may be more similar to each other. This becomes especially obvious on the tagma borders. An underlying reason for this lies in the appendage identity being determined by Hox genes. Put simply, Hox gene expression occurs with a gradient along the body, and the expression of different Hox genes overlaps with each other in certain areas, which results in "mixed" morphologies. This effect has been well studied in the maxillipeds of the amphipodan crustacean Parhyale hawaiiensis (e.g. Averof et al. 2010, see also Sharma et al. 2014b for Hox gene expression in scorpions and its possible effects on tagmosis).

The same effect occurs also on segments without appendages. In the above mentioned tagmosis patterns (Figs 1,2), post-ocular segment 14 turned out to be difficult in its tagma identity. It shares certain characters with the segments anterior to it, others with those posterior to it.

Therefore, an approach to understand tagmosis in any arthropodan group requires a clear set of tagmosis criteria, which need then to be checked for their absence in the investigated body area to achieve an internal coherence in argumentation.

The interpretation of the evolution of tagmosis of modern scorpions as proposed here does not demand any doublings or loss of segments. It explains observations from embryology and palaeontology without additional assumptions; therefore it is more parsimonious than previous reconstructions. We are aware that the interpretation differs from previous ones. Is there a reason why earlier reconstructions led to different results?

It seems that major hindrances of simple evolutionary reconstruction are the historical burden and assumptions. For example, the idea that early representatives of Scorpionida should already possess pectines is an assumption inspired by modern representatives. Yet, it was not simply compatible with the observation that they bore five pairs of book lungs and consequently triggered the idea that an additional segment must have appeared.

It also seems that the idea that all representatives of Euchelicerata have a prosoma composed of the ocular 

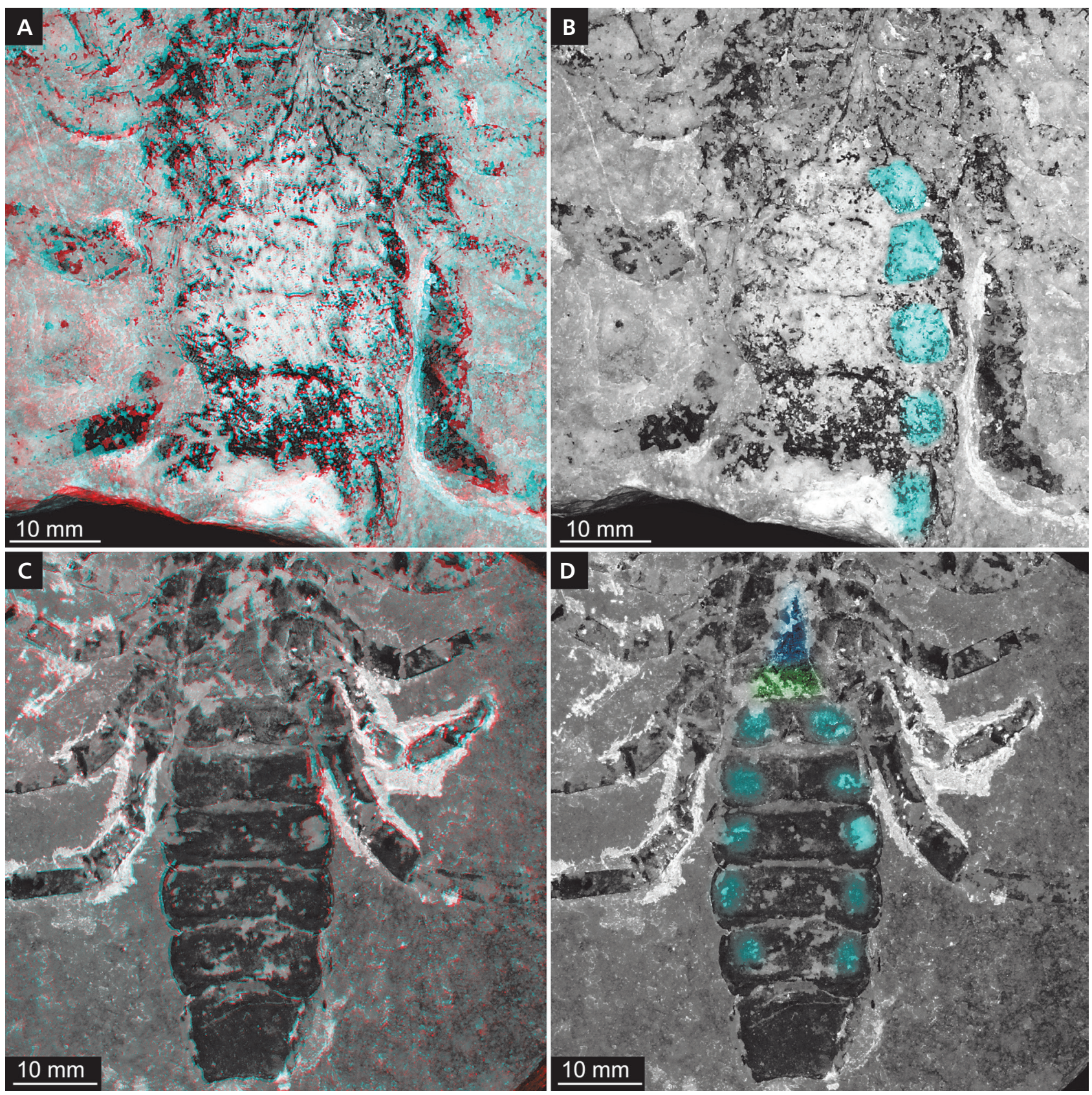

Figure 6. Book lungs of the mid-Silurian scorpion Eramoscorpius brucensis from the Eramosa Formation, Canada. • A, B - ROM 53247; A - stereo image; B - same as A, but without stereo effect and with colour-marked structures; the specimen clearly shows five segments (post-ocular segments 9-13) with sub-similar lateral depressions (cyan; see 3D information in A), which are, in our view, best interpreted as book lungs; Waddington et al. (2015) suggested that there could be pectines on the first segment, yet the stereo image (A) reveals that this segment is very similar in morphology to the next posterior segment. $-\mathrm{C}, \mathrm{D}-\mathrm{ROM} 50048$; $\mathrm{C}$ - stereo image; D - same as C, but without stereo effect and with colour-marked structures: blue = sternum; green = genital operculum; cyan = book lungs; also this specimen possesses five pairs of depressions on subsequent segments, presumably book lungs.

segment plus post-ocular segments $1-6$ and an opisthosoma with post-ocular segments 7-19 (or some fewer) has completely blocked recognising true functional tagmata. For example, Dunlop \& Lamsdell (2017) argue that tagmata are recognised by the differentiation of the appendages; they also argue that prosoma and opisthosoma are true tagmata. As pointed out above, there is no early node within Euchelicerata in which the opisthosoma segments would have uniform types of appendages. Hence the opisthosoma is in fact always only the "leftover" tagma without fulfilling any proper criteria. Also, Dunlop \& Lamsdell (2017) do not consequently apply 

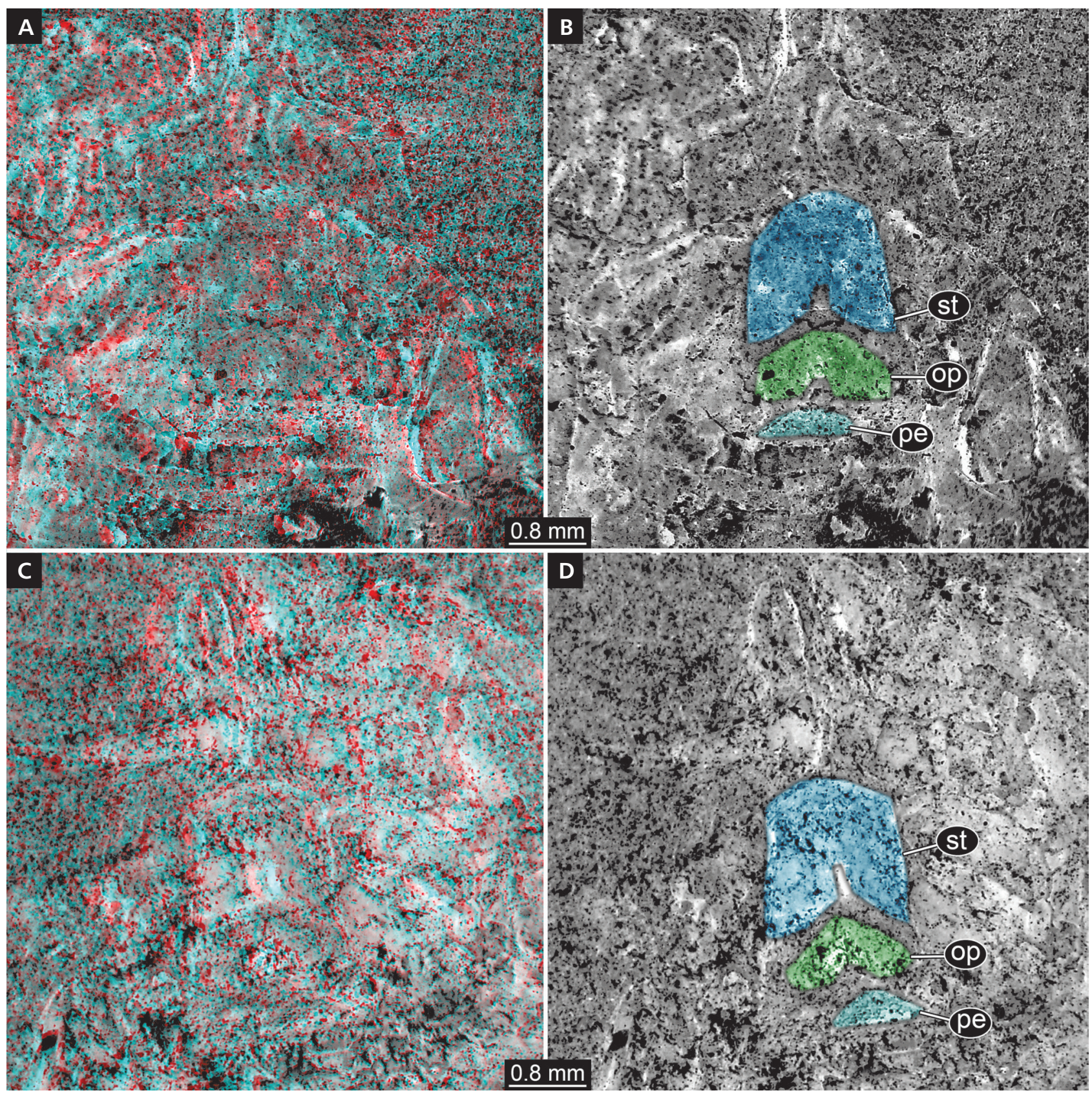

Figure 7. Sternum and associated structures of the Upper Carboniferous scorpion Pseudobuthiscorpius labiosus (possibly synonymous to Compsoscorpius buthiformis), NHM I1555, from the Coal Measures, Coseley, England. • A, B - part of the specimen, A - stereo image of part; B - same as A, but without stereo effect and with colour-marked structures. $\cdot \mathrm{C}, \mathrm{D}$ - counterpart; C - stereo image of counterpart; D - same as C, but without stereo effect and with colour-marked structures. Sternum (blue) now with pentagonal shape, genital operculum (green) clearly separate, and separate plate (cyan) from where the pectines arise. Abbreviations: op - genital operculum; pe - sternal plate of pectinal segment; st - sternum.

their own criterion for tagma recognition; for example, in Weinbergina opitzi the appendage of post-ocular segment 7 appears to be (sub-)similar to the further anterior ones, but still post-ocular segment 7 is recognised as opisthosoma segment 1 (Dunlop \& Lamsdell 2017, fig. 2).

It might be an effective strategy to accept that the prosoma-opisthosoma boundary is a mere orientation point for counting segments. It might represent a true tagma boundary in some groups, but will not do so in others. Tagmosis should be characterised by discrete criteria (as outlined above), based on direct observation on actual specimens, including fossils and different ontogenetic stages. A strict phylogenetic framework is necessary for character polarisation. And, maybe most important, the interpretations should be made independently from any historical assumptions. 


\section{Acknowledgements}

Jason Dunlop, Berlin, as well as one anonymous reviewer provided helpful comments on an earlier version of this manuscript. We would like to thank Jean-Bernard Caron and Janet Waddington, Toronto, and Claire Mellish, London, for providing access to the specimens. We are grateful to J. Matthias Starck, Munich, for inspiring discussions. The research visit of $\mathrm{CH}$ to the NHM London was made possible by a grant from the European Commission's (FP 6) Integrated Infrastructure Initiative program SYNTHESYS (GB-TAF-4057). JTH is currently funded by the Volkswagen Foundation with a Lichtenberg professorship. This study is part of a project kindly funded by the German Research Foundation (DFG) under HA 7066/3-1.

\section{References}

Arango, C.P. 2002. Morphological phylogenetics of the sea spiders (Arthropoda: Pycnogonida). Organisms Diversity \& Evolution 2, 107-125. DOI 10.1078/1439-6092-00035

Arango, C.P. \& Wheeler, W.C. 2007. Phylogeny of the sea spiders (Arthropoda, Pycnogonida) based on direct optimization of six loci and morphology. Cladistics 23, 255-293. DOI 10.1111/j.1096-0031.2007.00143.x

Assis, L.C. 2009. Coherence, correspondence, and the renaissance of morphology in phylogenetic systematics. Cladistics 25, 528-544. DOI 10.1111/j.1096-0031.2009.00261.x

Averof, M., Pavlopoulos, A. \& Kontarakis, Z. 2010. Evolution of new appendage types by gradual changes in Hox gene expression - the case of crustacean maxillipeds. Palaeodiversity 3 (Suppl.), 141-146.

Ax, P. 1995. Das System der Metazoa I. Ein Lehrbuch der phylogenetischen Systematik. 226 pp. Gustav Fischer Verlag, Stuttgart.

Ballesteros, J.A. \& Sharma, P.P. 2019. A critical appraisal of the placement of Xiphosura (Chelicerata) with account of known sources of phylogenetic error. Systematic Biology 68(6), 896-917. DOI 10.1093/sysbio/syz011

Bergström, J., Stürmer, W. \& Winter, G. 1980. Palaeoisopus, Palaeopantopus and Palaeothea, pycnogonid arthropods from the Lower Devonian Hunsrück Slate, West Germany. Paläontologische Zeitschrift 54, 7-54. DOI 10.1007/BF02985882

Braddy, S.J., Aldridge, R.J., Gabbott, S.E. \& Theron, J.N. 1999. Lamellate book-gills in a late Ordovician eurypterid from the Soom Shale, South Africa: support for a eurypteridscorpion clade. Lethaia 32, 72-74.

DOI 10.1111/j.1502-3931.1999.tb00582.x

Brenneis, G., Ungerer, P. \& Scholtz, G. 2008. The chelifores of sea spiders (Arthropoda, Pycnogonida) are the appendages of the deutocerebral segment. Evolution \& Development 10, 717-724. DOI 10.1111/j.1525-142X.2008.00285.X

Briggs, D.E.G., Siveter, D.J., Siveter, D.J., Sutton, M.D., Garwood, R.J. \& LegG, D. 2012. Silurian horseshoe crab illuminates the evolution of arthropod limbs. Proceedings of the National Academy of Sciences 109, 15702-15705. DOI 10.1073/pnas.1205875109

Chen, J., Waloszex, D. \& MaAs, A. 2004. A new 'greatappendage' arthropod from the Lower Cambrian of China and homology of chelicerate chelicerae and raptorial anteroventral appendages. Lethaia 15, 3-20.

Donoghue, P.C. 2005. Saving the stem group - a contradiction in terms? Paleobiology 31, 553-558. DOI 10.1666/0094-8373(2005)031[0553:STSGCI]2.0.CO;2

Dunlop, J.A. 1998. The origins of tetrapulmonate book lungs and their significance for chelicerate phylogeny, 9-16. In Proceedings of the $17^{\text {th }}$ European Colloquium of Arachnology, Edinburgh.

Dunlop, J.A. 2002. Arthropods from the Lower Devonian Severnaya Zemlya Formation of October Revolution Island (Russia). Geodiversitas 24, 349-379.

Dunlop, J.A. 2010. Geological history and phylogeny of Chelicerata. Arthropod Structure \& Development 39, 124-142. DOI 10.1016/j.asd.2010.01.003

Dunlop, J.A. \& Arango, C.P. 2005. Pycnogonid affinities: a review. Journal of Zoological Systematics and Evolutionary Research 43, 8-21. DOI 10.1111/j.1439-0469.2004.00284.x

Dunlop, J.A. \& Lamsdell, J.C. 2017. Segmentation and tagmosis in Chelicerata. Arthropod Structure \& Development 46, 395-418. DOI 10.1016/j.asd.2016.05.002

Dunlop, J.A. \& Webster, M. 1999. Fossil evidence, terrestrialization and arachnid phylogeny. Journal of Arachnology 27, 86-93.

Dunlop, J.A., Tetlie, E.O. \& Prendini, L. 2008. Reinterpretation of the Silurian scorpion Proscorpius osborni (Whitfield): integrating data from Palaeozoic and Recent scorpions. Palaeontology 51, 303-320. DOI 10.1111/j.1475-4983.2007.00749.x

Edgecombe, G.D. \& LegG, D.A. 2014. Origins and early evolution of arthropods. Palaeontology 57, 457-468. DOI 10.1111/pala.12105

EldRedge, N. 1974. Revision of the suborder Synziphosurina (Chelicerata, Merostomata), with remarks on merostome phylogeny. American Museum Novitates 2543, 1-41.

FARLEY, R.D. 2005. Developmental changes in the embryo, pronymph, and first molt of the scorpion Centruroides vittatus (Scorpiones: Buthidae). Journal of Morphology 265, 1-27. DOI 10.1002/jmor.10227

Garwood, R.J. \& Dunlop, J. 2014. Three-dimensional reconstruction and the phylogeny of extinct chelicerate orders. PeerJ 2, e641. DOI 10.7717/peerj.641

GiRibet, G. 2018. Current views on chelicerate phylogeny - A tribute to Peter Weygoldt. Zoologischer Anzeiger 273, 7-13. DOI 10.1016/j.jcz.2018.01.004

HAMMEN, L. VAN DER 1963. The addition of segments during the postembryonic ontogenesis of the Actinotrichida (Acarida) and its importance for the recognition of the primary subdivision of the body and the original segmentation. Acarologia 5, 443-457. 
HAMmEn, L. VAN DER 1980. Glossary of acarological terminology, Vol. 1 General terminology. 245 pp. Dr. W. Junk, The Hague.

Haug, C. \& Rötzer, M.A.I.N. 2018. The ontogeny of Limulus polyphemus (Xiphosura s. str., Euchelicerata) revised: looking "under the skin". Development Genes and Evolution 228, 49-61. DOI 10.1007/s00427-018-0603-1

Haug, C., Haug, J.T., Waloszek, D., Maas, A., Frattigiani, R. \& Liebau, S. 2009. New methods to document fossils from lithographic limestones of southern Germany and Lebanon. Palaeontologia Electronica 12(3), 6T, 12p.

Haug, C., Sallam, W.S., Maas, A., Waloszek, D., Kutschera, V. \& Haug, J.T. 2012b. Tagmatization in Stomatopoda reconsidering functional units of modern-day mantis shrimps (Verunipeltata, Hoplocarida) and implications for the interpretation of fossils. Frontiers in Zoology 9, art. 31. DOI 10.1186/1742-9994-9-31

Haug, C., Van Roy, P., Leipner, A., Funch, P., Rudkin, D.M., Schöllmann, L. \& Haug, J.T. 2012a. A holomorph approach to xiphosuran evolution-a case study on the ontogeny of Euproops. Development Genes and Evolution 222, 253-268. DOI 10.1007/s00427-012-0407-7

Haug, J.T., Briggs, D.E.G. \& Haug, C. 2012b. Morphology and function in the Cambrian Burgess Shale megacheiran arthropod Leanchoilia superlata and the application of a descriptive matrix. BMC Evolutionary Biology 12, art. 162. DOI 10.1186/1471-2148-12-162

Haug, J.T., Haug, C. \& Ehrlich, M. 2008. First fossil stomatopod larva (Arthropoda: Crustacea) and a new way of documenting Solnhofen fossils (Upper Jurassic, Southern Germany). Palaeodiversity 1, 103-109.

Haug, J.T., Haug, C., Kutschera, V., Mayer, G., Maas, A., Liebau, S., Castellani, C., Wolfram, U., Clarkson, E.N.K. \& WALOSZEK, D. 2011. Autofluorescence imaging, an excellent tool for comparative morphology. Journal of Microscopy 244, 259-272. DOI 10.1111/j.1365-2818.2011.03534.x

Haug, J.T., MaAs, A., Haug, C. \& Waloszek, D. 2013. Chapter 2. Evolution of crustacean appendages, 34-73. In WATLING, L. \& Thiel, M. (eds) Vol. 1. Functional Morphology and Diversity. The Natural History of the Crustacea. Oxford University Press, Oxford.

DOI 10.1093/acprof:osobl/9780195398038.003.0002

Haug, J.T., Waloszek, D., MaAs, A., Liu, Y. \& Haug, C. 2012a. Functional morphology, ontogeny and evolution of mantis shrimp-like predators in the Cambrian. Palaeontology 55, 369-399. DOI 10.1111/j.1475-4983.2011.01124.x

Hedgpeth, J.W. 1947. On the evolutionary significance of the Pycnogonida. Smithsonian Miscellaneous Collection 106, $1-53$.

Hennig, W. 1966. Phylogenetic systematics. 263 pp. University of Illinois Press, Urbana, IL.

Jager, M., Murienne, J., Clabaut, C., Deutsch, J., Le Guyader, H. \& Manuel, M. 2006. Homology of arthropod anterior appendages revealed by Hox gene expression in a sea spider. Nature 441, 506-508. DOI 10.1038/nature04591

Jeram, A.J. 1998. Phylogeny, classification and evolution of
Silurian and Devonian scorpions, 17-31. In Proceedings of the $17^{\text {th }}$ European Colloquium of Arachnology, Edinburgh.

Kerp, H. \& Bomfleur, B. 2011. Photography of plant fossils new techniques, old tricks. Review of Palaeobotany and Palynology 166, 117-151.

DOI 10.1016/j.revpalbo.2011.05.001

KJellesvig-Waering, E.N. 1986. A restudy of the fossil Scorpionida of the world. Palaeontographica Americana 55, $1-287$.

Klussmann-Fricke, B.J. \& Wirkner, C.S. 2016. Comparative morphology of the hemolymph vascular system in Uropygi and Amblypygi (Arachnida): complex correspondences support Arachnopulmonata. Journal of Morphology 277, 1084-1103. DOI 10.1002/jmor.20559

KüHL, G., Poschmann, M. \& Rust, J. 2013. A ten-legged sea spider (Arthropoda: Pycnogonida) from the Lower Devonian Hunsrück Slate (Germany). Geological Magazine 150, 556-564. DOI 10.1017/S0016756812001033

Lamsdell, J.C. 2013. Revised systematics of Palaeozoic 'horseshoe crabs' and the myth of monophyletic Xiphosura. Zoological Journal of the Linnean Society 167, 1-27. DOI 10.1111/j.1096-3642.2012.00874.x

LAMSDELL, J.C. 2016. Horseshoe crab phylogeny and independent colonizations of fresh water: ecological invasion as a driver for morphological innovation. Palaeontology 59, 181-194. DOI 10.1111/pala.12220

LEGG, D. 2013. Multi-segmented arthropods from the Middle Cambrian of British Columbia (Canada). Journal of Paleontology 87, 493-501. DOI 10.1666/12-112.1

Lehmann, W.M. 1956. Beobachtungen an Weinbergina opitzi (Merost., Devon). Senckenbergiana lethaia 37, 67-77.

Liu, Y., Hou, X.G. \& Bergström, J. 2007. Chengjiang arthropod Leanchoilia illecebrosa (Hou, 1987) reconsidered. GFF 129, 263-272. DOI 10.1080/11035890701293263

MAAs, A. \& WALOSZEK, D. 2001. Cambrian derivatives of the early arthropod stem lineage, pentastomids, tardigrades and lobopodians - an 'Orsten' perspective. Zoologischer Anzeiger A Journal of Comparative Zoology 240, 451-459. DOI 10.1078/0044-5231-00053

MaAs,A., Waloszek, D., Chen, J., Braun,A., Wang, X. \& Huang,D. 2004. Phylogeny and life habits of early arthropods predation in the Early Cambrian sea. Progress in Natural Science 14, 158-166.

\section{DOI 10.1080/10020070412331343301}

Manuel, M., Jager, M., Murienne, J., Clabaut, C. \& Le Guyader, H. 2006. Hox genes in sea spiders (Pycnogonida) and the homology of arthropod head segments. Development Genes and Evolution 216, 481-491. DOI 10.1007/s00427-006-0095-2

Marshall, D.J., Lamsdell, J.C., Shrinev, E. \& Braddy, S.J. 2014. A diverse chasmataspidid (Arthropoda: Chelicerata) fauna from the Early Devonian (Lochkovian) of Siberia. Palaeontology 57, 631-655. DOI 10.1111/pala.12080

Minelli, A. 2016. Species diversity vs. morphological disparity in the light of evolutionary developmental biology. Annals of Botany 117, 781-794. DOI 10.1093/aob/mcv134 
MoczeK, A.P. 2010. Phenotypic plasticity and diversity in insects. Philosophical Transactions of the Royal Society B: Biological Sciences 365, 593-603. DOI 10.1098/rstb.2009.0263

Moczek, A.P., Sultan, S., Foster, S., Ledón-Rettig, C., Dworkin, I., Nijhout, H.F., Abouheif, E. \& Pfennig, D.W. 2011. The role of developmental plasticity in evolutionary innovation. Proceedings of the Royal Society B: Biological Sciences 278, 2705-2713. DOI 10.1098/rspb.2011.0971

Moore, R.A., Briggs, D.E.G. \& Bartels, C. 2005b. A new specimen of Weinbergina opitzi (Chelicerata: Xiphosura) from the Lower Devonian Hunsrück Slate, Germany. Paläontologische Zeitschrift 79, 399-408. DOI 10.1007/BF02991931

Moore, R.A., McKenzie, S.C. \& Lieberman, B.S. 2007. A Carboniferous synziphosurine (Xiphosura) from the Bear Gulch Limestone, Montana, USA. Palaeontology 50, 1013-1019. DOI 10.1111/j.1475-4983.2007.00685.x

Moore, R.A., Briggs, D.E.G., Braddy, S.J., Anderson, L.I., Mikulic, D.G. \& Kluessendorf, J. 2005a. A new synziphosurine (Chelicerata: Xiphosura) from the late Llandovery (Silurian) Waukesha lagerstätte, Wisconsin, USA. Journal of Paleontology 79, 242-250.

DOI 10.1666/0022-3360(2005)079<0242:ANSCXF $>2.0 . C O ; 2$

Moore, R.A., Briggs, D.E.G., Braddy, S.J. \& Shultz, J.W. 2011. Synziphosurines (Xiphosura: Chelicerata) from the Silurian of Iowa. Journal of Paleontology 85, 83-91. DOI 10.1666/10-057.1

Pechmann, M. \& PrPic, N.M. 2009. Appendage patterning in the South American bird spider Acanthoscurria geniculata (Araneae: Mygalomorphae). Development Genes and Evolution 219, 189-198. DOI 10.1007/s00427-009-0279-7

Poschmann, M. \& Dunlop, J.A. 2006. A new sea spider (Arthropoda: Pycnogonida) with a flagelliform telson from the Lower Devonian Hunsrück Slate, Germany. Palaeontology 49, 983-989. DOI 10.1111/j.1475-4983.2006.00583.x

Poschmann, M., Dunlop, J.A., Kamenz, C. \& Scholtz, G. 2008. The Lower Devonian scorpion Waeringoscorpio and the respiratory nature of its filamentous structures, with the description of a new species from the Westerwald area, Germany. Paläontologische Zeitschrift 82, 418-436. DOI 10.1007/BF03184431

REIF, W.E. 2002. Evolution of organ systems: phylogeny, function and reciprocal illumination. Senckenbergiana lethaea 82, 356-366. DOI 10.1007/BF03043794

Scholl, G. 1977. Beiträge zur Embryonalentwicklung von Limulus polyphemus L. (Chelicerata, Xiphosura). Zoomorphologie 86, 99-154. DOI 10.1007/BF00995521

Scholtz, G. \& Edgecombe, G.D. 2006. The evolution of arthropod heads: reconciling morphological, developmental and palaeontological evidence. Development Genes and Evolution 216, 395-415. DOI 10.1007/s00427-006-0085-4

Selden, P.A., Lamsdell, J.C. \& Qi, L. 2015. An unusual euchelicerate linking horseshoe crabs and eurypterids, from the Lower Devonian (Lochkovian) of Yunnan, China. Zoologica Scripta 44, 645-652. DOI 10.1111/zsc.12124
Sharma, P.P., Kaluziak, S.T., Perez-Porro, A.R., Gonzalez, V.L., Hormiga, G., Wheeler, W.C. \& Giribet, G. 2014a. Phylogenomic interrogation of Arachnida reveals systemic conflicts in phylogenetic signal. Molecular Biology and Evolution 31, 2963-2984. DOI 10.1093/molbev/msu235

Sharma, P.P., Schwager, E.E., Extavour, C.G., \& Wheeler, W.C. 2014b. Hox gene duplications correlate with posterior heteronomy in scorpions. Proceedings of the Royal Society B: Biological Sciences 281, 20140661.

DOI 10.1098/rspb.2014.0661

Shultz, J.W. 2001. Gross muscular anatomy of Limulus polyphemus (Xiphosura, Chelicerata) and its bearing on evolution in the Arachnida. Journal of Arachnology 29, 283-303. DOI 10.1636/0161-8202(2001)029[0283:GMAOLP]2.0.CO;2

Shultz, J.W. 2007a. A phylogenetic analysis of the arachnid orders based on morphological characters. Zoological Journal of the Linnean Society 150, 221-265.

DOI 10.1111/j.1096-3642.2007.00284.x

Shultz, J.W. 2007b. Morphology of the prosomal endoskeleton of Scorpiones (Arachnida) and a new hypothesis for the evolution of cuticular cephalic endoskeletons in arthropods. Arthropod Structure \& Development 36, 77-102.

DOI 10.1016/j.asd.2006.08.001

SNODgrass, R.E. 1948. The feeding organs of Arachnida, including mites and ticks. Smithsonian Miscellaneous Collections 110, 1-93.

SolEglad, M.E. \& Fet, V. 2003. The scorpion sternum: structure and phylogeny (Scorpiones: Orthosterni). Euscorpius 2003(5), 1-34. DOI 10.18590/euscorpius.2003.vol2003.iss5.1

Stürmer, W. \& Bergström, J. 1981. Weinbergina, a xiphosuran arthropod from the Devonian Hunsrück Slate. $\mathrm{Pa}$ läontologische Zeitschrift 55, 237-255.

DOI 10.1007/BF02988142

Sutton, M.D., Briggs, D.E.G., Siveter, D.J., Siveter, D.J. \& ORR, P.J. 2002. The arthropod Offacolus kingi (Chelicerata) from the Silurian of Herefordshire, England: computer based morphological reconstructions and phylogenetic affinities. Proceedings of the Royal Society of London B: Biological Sciences 269, 1195-1203.

DOI 10.1098/rspb.2002.1986

Tollerton, V.P. 1989. Morphology, taxonomy, and classification of the order Eurypterida Burmeister, 1843. Journal of Paleontology 63, 642-657. DOI 10.1017/S0022336000041275

Vilpoux, K. \& WaloszeK, D. 2003. Larval development and morphogenesis of the sea spider Pycnogonum litorale (Ström, 1762) and the tagmosis of the body of Pantopoda. Arthropod Structure \& Development 32, 349-383.

DOI 10.1016/j.asd.2003.09.004

Vogel, B.R. \& Durden, C.J. 1966. The occurrence of stigmata in a Carboniferous scorpion. Journal of Paleontology 40, 655-658.

Waddington, J., Rudkin, D.M. \& Dunlop, J.A. 2015. A new mid-Silurian aquatic scorpion-one step closer to land? Biology Letters 11, 20140815. DOI 10.1098/rsbl.2014.0815

Walossek, D. \& Müller, K.J. 1998. Cambrian 'Orsten'-type arthropods and the phylogeny of Crustacea, 139-153. In 
ForTey, R.A. \& Thomas, R.H. (eds) Arthropod relationships, Systematics Association Special Volume Series 55. Chapman \& Hall, London. DOI 10.1007/978-94-011-4904-4_12

Waterston, C.D. 1975. Gill structure in the Lower Devonian eurypterid Tarsopterella scotica. Fossils and Strata 4, 241-254.

Weygoldt, P. \& Paulus, H.F. 1979. Untersuchungen zur Morphologie, Taxonomie und Phylogenie der Chelicerata 1 II.
Cladogramme und die Entfaltung der Chelicerata. Journal of Zoological Systematics and Evolutionary Research 17, 177-200. DOI 10.1111/j.1439-0469.1979.tb00699.x

Wolff, C. \& Scholtz, G. 2008. The clonal composition of biramous and uniramous arthropod limbs. Proceedings of the Royal Society B: Biological Sciences 275, 1023-1028. DOI 10.1098/rspb.2007.1327 